\section{Evaluation of Midwinter Cold Hardiness among 25 Rabbiteye Blueberry Cultivars}

\author{
Mark K. Ehlenfeldt ${ }^{1}$ \\ United States Department of Agriculture, Agricultural Research Service, \\ Blueberry and Cranberry Research Center, 125A Lake Oswego Road, \\ Chatsworth, NJ 08019
}

Elizabeth L. Ogden and Lisa J. Rowland

U.S. Department of Agriculture, Agricultural Research Service, Henry A. Wallace Beltsville Agricultural Research Center, Fruit Laboratory, Building 010A, BARC-West, Beltsville, MD 20705

\section{Bryan Vinyard \\ U.S. Department of Agriculture, Agricultural Research Service, Henry A. Wallace Beltsville Agricultural Research Center, Biometrical Consulting Service, Building 005, BARC-West, Beltsville, MD 20705}

\section{Additional index words. dehardening, freezing tolerance, flower bud}

\begin{abstract}
The midwinter cold hardiness of 25 rabbiteye ( $V$. ashei) blueberry cultivars was assayed across 2 years using a shoot freezing assay. LT $_{50}$ values (i.e. temperature at which $50 \%$ of buds are damaged) for the cultivars ranged from $-24.9^{\circ} \mathrm{C}$ for 'Pearl River' $(\mathrm{a} 5 \%$ $V$. ashei derivative) to $-13.7^{\circ} \mathrm{C}$ for 'Chaucer'. Under New Jersey conditions, numerous cultivars were observed to exhibit dimorphism for dormant floral bud size. Comparisons of bud dimorphism with $\mathrm{LT}_{50}$ values, found dimorphism more common in cultivars with lower floral bud hardiness. $\mathbf{L T} \mathbf{T}_{50}$ values generally supported empirical observations of winter hardiness, but exceptions suggest that additional factors contribute to observed winter hardiness under field conditions.
\end{abstract}

There are presently $>150,000$ acres of cultivated blueberries (Vaccinium section Cyanococcus) in North America (Trinka, 1996; Ballington, 2001), and the United States is the world's leading producer. In a survey of the blueberry research and extension scientists in the U.S., lack of winter hardiness and susceptibility to spring frosts have been identified as two of the most important problems of current cultivars (Moore, 1993). In nearly all blueberry growing areas in the U.S., economic losses from early spring frosts can be significant, and in the northern production regions, winter damage is considered the major factor limiting yields (Hanson and Hancock, 1990; Moore, 1994). As blueberry germplasm has become more diverse, there have been increased concerns whether resulting selections and cultivars are sufficiently winter hardy, especially if southern-adapted germplasm comprises a significant part of the genetic background. Rabbiteye blueberry ( $V$. ashei Reade) particularly has been considered relatively cold-sensitive (Galletta and Ballington, 1996).

In recent years, in the process of trying to develop late-flowering, early-ripening $V$. ashei-type cultivars for Georgia (through $V$. constablaei Gray introgression) (Ehlenfeldt and Rowland, in press), it became apparent

Received for publication 17 Nov. 2005. Accepted for publication 22 Dec. 2005.

${ }^{1}$ To whom reprint request should be addressed; e-mail mehlenfeldt@ars.usda.gov. that many of the families and selections from such families were sufficiently winter hardy to produce crops in New Jersey in most years. This winter hardiness along with superior plant vigor has led to a continuing attempt to develop northern-adapted rabbiteye-type cultivars. One strategy for optimizing the winter hardiness of the hybrids is to use rabbiteye parents that combine desired traits with maximum winter hardiness. To this end, we examined midwinter cold hardiness under field conditions, among observations of winter hardiness among rabbiteye cultivars are also discussed.

\section{Materials and Methods}

Plant material. In total, 25 rabbiteye blueberry cultivars were used for this study. Notes on the origins and unusual germplasm compositions are given in Table 1. Shoots came from pairs of mature plants in experimental plantings at the P.E. Marucci Center for Blueberry and Cranberry Research and Extension (Rutgers University) in Chatsworth, N.J. Detached shoots were collected on 8 Jan. 2004 and on 10 Jan. 2005 to determine floral-bud cold hardiness. Previous studies of highbush and rabbiteye have shown this time period to be one at which plants have achieved maximum cold hardiness (Muthalif and Rowland, 1994). All plants used for shoot collection were at least 4 to 5 years old, and were selected for as much uniformity as possible. Most samples 25 rabbiteye blueberry genotypes. Empirical were from terminal shoots taken from upper portions of the bush.

Determination of flower bud cold hardiness. For the freeze-thaw protocol, three 5- to 6-cm-long shoots, each with three to eight flower buds, were used for each treatment as described previously by Arora et al. (2004). Treatment temperatures chosen for the fully cold-acclimated buds covered a range from -10 to $-28^{\circ} \mathrm{C}$ (the lowest temperature that the glycol freezing bath would consistently reach) in $2{ }^{\circ} \mathrm{C}$ increments, to cover a potential range of $0 \%$ to $100 \%$ injury to blueberry buds for most genotypes (Arora et al., 1997). Shoots were removed from the freezing bath at their respective selected treatment temperatures, thawed overnight at $4^{\circ} \mathrm{C}$, then incubated at 20 ${ }^{\circ} \mathrm{C}$ for $24 \mathrm{~h}$. The three most apical buds were then dissected and observed for injury (visual browning of the ovaries in individual flowers) (Arora et al., 2000; Flinn and Ashworth, 1994). Each bud was rated for percentage of injured ovaries and bud cold hardiness was defined as the temperature causing 50\% injury overall $\left(\mathrm{LT}_{50}\right)$.

Statistical analysis of cold hardiness data. Bootstrap estimates (Manly, 1997) of $\mathrm{LT}_{50}$ values and their 95\% fiducial confidence intervals were calculated using Proc Probit (SAS Institute, 1999) for each cultivar $\times$ year combination. The nine observed data points (three proximal buds on each of the three shoots) for each temperature were resampled ( $n=9$ with replacement) 10,000 times. A sigmoidal (i.e., logistic) regression model was fit to percentage of injury (browning) vs. treatment temperature for each of the 10,000 sets of resampled data, and the 10,000 resulting values of $\mathrm{LT}_{50}$ and their lower and upper confidence limits were averaged to obtain a bootstrap estimate for each cultivar $\times$ year. A one-way ANOVA was conducted on these $50 \mathrm{LT}_{50}$ estimates to compare the 25 cultivars using the duplicate year data. Cultivar $\times$ year (i.e., error) variability was partitioned into 5 sizes of variance groups so that the appropriate size of error variation was associated with each cultivar in the means comparison. The cultivar means comparison used the Sidak adjustment to ensure $\alpha=0.05$.

Bud size evaluations. On 11 Jan. 2005, the cultivars in were evaluated for uniformity of flower bud size. Ratings were done on a scale of 1 to 5 with $1=$ uniformly sized buds and 5 $=$ a substantial difference between the smallest and largest buds on the cultivar.

\section{Results and Discussion}

Comparison of bud cold hardiness of blueberry genotypes. $\mathrm{LT}_{50}$ values for the coldacclimated rabbiteye cultivars across 2 years ranged from $-13.7^{\circ}$ ('Chaucer') to $-24.9^{\circ} \mathrm{C}$ ('Pearl River')(Table 1). The highbush cultivar Bluecrop, at comparable times across several years had $\mathrm{LT}_{50}$ values averaging -26 to $-27^{\circ} \mathrm{C}$. Due to the heterogeneity of between-year variation observed among these cultivars and the large number of cultivars evaluated there was considerable overlap in the statistical groupings. Year-to-year variation among $\mathrm{LT}_{50}$ values 
averaged $1.9^{\circ} \mathrm{C}$, and the cultivars were equally divided with respect to which year had a lower $\mathrm{LT}_{50}$ (data not shown). Four cultivars with particularly large variability between years were (listed for 2004 and 2005 in ${ }^{\circ} \mathrm{C}$, respectively): 'Black Giant' $(-10.1,-20.0)$, 'Owen' $(-12.2$, $-16.8)$, 'Early May' $(-17.6,-22.0)$, and 'Aliceblue' $(-17.6,-21.2)$. Across the remaining 22 cultivars, year-to-year variation averaged only $1.1^{\circ} \mathrm{C}$. The larger variability among the four cultivars mentioned was apparently due to higher baseline levels of damage in 2004 that biased their $\mathrm{LT}_{50}$ estimates upward.

Observations regarding ancestry. 'Pearl River', the only cultivar in the group that was $50 \%$ highbush, was also the most hardy. Although causation cannot be proven, this degree of hardiness appears to derive from the highbush component, since its rabbiteye parent, 'Beckyblue', was among the less hardy cultivars (ranked 23 of 26) in our evaluation, and 'Beckyblue's two other offspring, 'Aliceblue' and 'Chaucer' (both 'Beckyblue' O.P. seedlings), are similarly poor in terms of cold hardiness (ranked 17 of 26 and 26 of 26 , respectively). The other pertinent observation in identifying sources of cold hardiness is that 'Tifblue' and its offspring/descendants (herein defined as having 'Tifblue' as parent or grandparent) occupy 5 of the 13 positions on the hardier half of the distribution. 'Tifblue' itself was the fourth most hardy cultivar among those tested, and has been recognized elsewhere as one of the most hardy rabbiteye blueberry cultivars (Moore and Brown, 1971).

Rabbiteye floral bud size dimorphism. Under New Jersey conditions, rabbiteye cultivars were observed to have floral bud size dimorphism. This dimorphism was manifest as relatively tight, small, floral buds that were borne on shoots that terminated cane or branch growth, and larger, looser floral buds that were borne on short, nearly perpendicular twigs attached to the main cane. These short twigs were typically about $5 \mathrm{~cm}$ in length and usually had only two to three floral buds. This growth habit is peculiar to rabbiteye and is not observed on highbush cultivars. A ranking of rabbiteye cultivars for bud dimorphism is shown in Table 2 . Ratings of 1,2 , or 3 (1= most uniform sized) were observed across the entire $\mathrm{LT}_{50}$ distribution of Table 1 , but ratings of 4 or $5^{50}(5=$ maximally dimorphic) ratings were always found in the less hardy half of the distribution. Bud dimorphism therefore seems to suggest a possible propensity of a cultivar toward lower floral bud hardiness overall. In this context, it should be reiterated, that our $\mathrm{LT}_{50}$ assay samples were selected for uniformity and were primarily terminal shoots.
Field observations of rabbiteye winter hardiness. In several recent years $(2001,2003$, 2005) when 36 rabbiteye cultivars were rated for time of flowering, it was observed that significant differential damage had occurred among cultivars. In these years, rabbiteye cultivars that had substantial flower production were rated for their relative quantity of flowering. Flowering was rated on a three-category scale (good, moderate, fair). Using these ratings across the three years (data not shown), the rabbiteye cultivars were given a ranking for flower survival as follows: 'Baldwin' > 'Tifblue' > 'Coastal' $>$ 'Ethel'/'Satilla' > 'Walker' $>$ ('Bluebelle', 'Centurion', 'Choice') > ('Montgomery', 'Delite', 'Hagood', 'Powderblue') > ('Aliceblue', 'Premier', 'Southland', 'Briteblue'). Cultivars not listed performed poorly across all three of these "differential" years. An exception to this was 'Pearl River', which, because it is not pure rabbiteye, had not been evaluated specifically with the rabbiteye group, but had generally flowered well. What is notable in this ranking is that some cultivars that were relatively hardy in the controlled freezing assay (e.g., 'Suwanee', 'Homebell') did poorly under field conditions. Hence, midwinter hardiness is a necessary, but not exclusive requirement for effective "winter hardiness" (good flowering) under northern

Table 1. Bud cold hardiness $\left(\mathrm{LT}_{50}\right)$ values with standard error (SE), pedigree, and origin for 25 Vaccinium ashei blueberry cultivars evaluated in 2004 and 2005.

\begin{tabular}{lllll}
\hline Cultivar & \multicolumn{1}{c}{$\mathrm{LT}_{50}$} & $\mathrm{SE}$ & & \\
\hline Pearl River & $-24.9 \mathrm{a}^{\mathrm{z}}$ & $\left({ }^{\circ} \mathrm{C}\right)$ & Pedigree & Origin \\
Walker & $-23.7 \mathrm{a}-\mathrm{d}$ & 0.95 & G 136 (SHB) $\times$ Beckyblue & USDA-ARS, Poplarville, Miss. \\
Coastal & $-23.5 \mathrm{ab}$ & 0.50 & Unknown & Georgia, wild selection \\
Tifblue & $-23.2 \mathrm{ab}$ & 0.22 & Myers $\times$ Black Giant & Univ. Georgia \\
Premier & $-22.4 \mathrm{a}-\mathrm{f}$ & 0.95 & Ethel $\times$ Clara & USDA-ARS and Univ. Georgia \\
Powderblue & $-22.1 \mathrm{a}-\mathrm{d}$ & 0.50 & Tifblue $\times$ Homebell & USDA-ARS and Univ. Georgia \\
Suwanee & $-21.7 \mathrm{bc}$ & 0.22 & Tifblue $\times$ Menditoo & USDA-ARS and Univ. Georgia \\
Southland & $-21.2 \mathrm{~b}-\mathrm{d}$ & 0.22 & Unknown & Georgia, wild selection \\
Homebell & $-20.6 \mathrm{a}-\mathrm{g}$ & 0.95 & Garden Blue $\times$ Ethel & USDA-ARS and Univ. Georgia \\
Baldwin & $-20.4 \mathrm{c}-\mathrm{e}$ & 0.22 & Myers $\times$ Black Giant & USDA-ARS and Univ. Georgia \\
Ethel & $-20.0 \mathrm{~d}-\mathrm{f}$ & 0.22 & Tifblue $\times$ GA 6-40 (Myers $\times$ Black Giant) & USDA-ARS, Poplarville, Mississippi \\
Montgomery & $-19.8 \mathrm{~b}-\mathrm{g}$ & 0.95 & Unknown & Georgia, wild selection \\
Early May & $-19.8 \mathrm{a}-\mathrm{h}$ & 2.12 & NC 763 $\times$ Premier & N.C. State Univ. \\
Myers & $-19.8 \mathrm{c}-\mathrm{g}$ & 0.50 & Unknown & Georgia, wild selection \\
Climax & $-19.6 \mathrm{c}-\mathrm{g}$ & 0.50 & Unknown & Georgia, wild selection \\
Garden Blue & $-19.4 \mathrm{~b}-\mathrm{g}$ & 0.95 & Callaway $\times$ Ethel & USDA-ARS and Univ. Georgia \\
Aliceblue & $-19.4 \mathrm{a}-\mathrm{h}$ & 2.12 & Myers $\times$ Clara & USDA-ARS and N.C. State Univ. \\
Delite & $-19.1 \mathrm{~b}-\mathrm{g}$ & 0.95 & Beckyblue O.P. & Univ. Florida \\
Bluegem & $-18.9 \mathrm{~b}-\mathrm{g}$ & 0.95 & Bluebelle $\times$ T-15 & USDA-ARS and Univ. Georgia \\
Brightwell & $-18.3 \mathrm{e}-\mathrm{g}$ & 0.50 & T-31 (Ethel $\times$ Callaway) O.P. & Univ. Florida \\
Callaway & $-17.7 \mathrm{fg}$ & 0.50 & Tifblue $\times$ Menditoo & USDA-ARS and Univ. Georgia \\
Beckyblue & $-16.9 \mathrm{~g}$ & 0.50 & Myers $\times$ Black Giant & Univ. Georgia \\
Black Giant & $-15.0 \mathrm{a}-\mathrm{h}$ & 4.93 & Fla 6-138 $\times$ E 96 (HB) & Univ. Florida \\
Owen & $-14.5 \mathrm{~b}-\mathrm{h}$ & 2.12 & Unknown & Georgia, wild selection \\
Chaucer & $-13.7 \mathrm{~h}$ & 0.50 & Unknown & Georgia, wild selection \\
\hline
\end{tabular}

${ }^{2}$ Mean separation among genotypes within column; Sidak-adjusted to ensure $\alpha=0.05$.

${ }^{y} \mathrm{SHB}=$ southern highbush, $\mathrm{HB}=$ highbush. All other parents are hexaploid rabbiteye blueberry ( $V$. ashei).

‘'Beckyblue' is probably pure rabbiteye, as noted by Sherman and Sharpe (1978).

Table 2. Floral bud size dimorphism among 36 rabbiteye blueberry cultivars in New Jersey as rated in January 2005. Rated on a scale of 1 to 5 , with $1=$ uniform in size, 5 = maximally dimorphic.

\begin{tabular}{|c|c|}
\hline Rating & Cultivar $^{2}$ \\
\hline 1 & Baldwin, Black Giant, Centurion, Clara, Early May, Hagood, Owen, Premier, Tifblue \\
\hline 3 & Austin, Briteblue, Chaucer, Climax, Coastal, Delite, Ethel, Garden Blue, Homebell, Ira, Menditoo, Powderblue, Woodard \\
\hline
\end{tabular}

${ }^{2}$ Several cultivars listed in this table were not part of the laboratory bud cold hardiness evaluation.

y'Satilla' is considered to be synonymous with 'Ethel'. This clone had a similar but distinct phenotype compared to 'Ethel' and is therefore listed separately. 
climatic conditions. There are multiple aspects to effective expression of cold hardiness/adaptation. Among them are 1) midwinter bud cold hardiness, 2) timing and rates of spring deacclimation, 3 ) variability among buds for cold hardiness/reserve buds, 4) degree of flower damage by late spring frosts, and 5) the effect of previous season fall temperatures as they influence midwinter cold hardiness. These conditions may all play a role in determining practical winter hardiness. If these cultivars are to be used as breeding parents for northernadapted rabbiteye, consideration should be made of cold hardiness along with as many other desired characteristics as possible.

\section{Literature Cited}

Arora, R., L.J. Rowland, E.L. Ogden, A.L. Dhanaraj, C.O. Marian, M.K. Ehlenfeldt, and B. Vinyard. 2004. Dehardening kinetics, bud development, and dehydrin metabolism in blueberry cultivars during deacclimation at constant, warm temperatures. J. Amer. Soc. Hort. Sci. 129:667-674.
Arora, R., L.J. Rowland, and G.R. Panta. 1997. Chill responsive dehydrins in blueberry: are they associated with cold hardiness or dormancy transitions? Physiol. Plant. 101: 8-16.

Ballington, J.R. 2001. Collection, utilization, and preservation of genetic resources in Vaccinium. HortScience 36:213-220.

Ehlenfeldt, M.K. and L.J. Rowland. Cold-hardiness of $V$. ashei and $V$. constablaei germplasm, and the potential for northern-adapted rabbiteye cultivars. Acta Hort. (in press).

Flinn, C.L. and E.N. Ashworth. 1994. Blueberry flower-bud hardiness is not estimated by differential thermal analysis. J. Amer. Soc. Hort. Sci. 119:295-298.

Galletta, G.J. and J.R. Ballington. 1996. Blueberries, cranberries, and lingonberries, p. 1-107. In: J. Janick and J.N. Moore (eds.). Fruit breeding. vol. 2. Vine and small fruit crops. John Wiley \& Sons, Inc., New York.

Hancock, J.F., J.W. Nelson, H.C. Bittenbender, P.W. Callow, J.S. Cameron, S.L. Krebs, M.P. Pritts, and C.M. Schumann. 1987. Variation among highbush blueberry cultivars in susceptibility to spring frost. J. Amer. Soc. Hort. Sci.
112:702-706

Hanson, E.J. and J.F. Hancock. 1990. Highbush blueberry cultivars and production trends. Fruit Var. J. 44:77-81.

Manly, B.F.J. 1997. Randomization, bootstrap and Monte Carlo methods in biology. 2nd ed. Chapman \& Hall, London.

Moore, J.N. 1993. The blueberry industry of North America. Acta Hort. 346:15-26.

Moore, J.N. 1994. The blueberry industry of North America. HortTechnology 4:96-102.

Moore, J.N. and G.R.Brown. 1971. Susceptibility of blackberry and blueberry cultivars to winter injury. Fruit Var. Hort. Dig. 25:31-32.

Muthalif, M.M. and L.J. Rowland. 1994. Identification of dehydrin-like proteins responsive to chilling in floral buds of blueberry ( $\mathrm{Vac}$ cinium, section Cyanococcus). Plant Physiol. 104:1439-1447.

SAS Institute, 1999. SAS/STAT user's guide. release 8.0. SAS Inst., Cary, N.C.

Sherman, W.B. and R.H. Sharpe. 1978. 'Beckyblue' blueberry. HortScience 13:61.

Trinka, D.L. 1996. Production trends in the cultivated blueberry industry of North America. Acta Hort. 446:33-36. 